
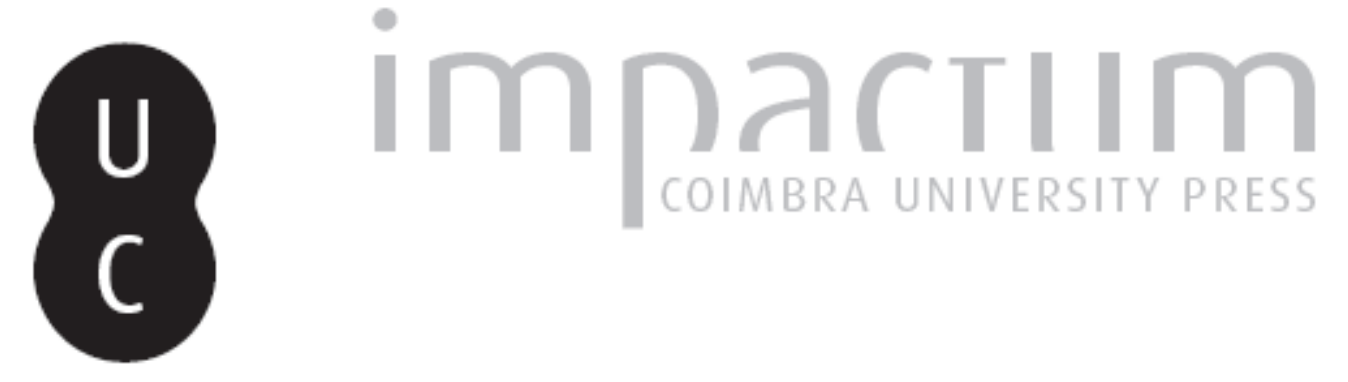

\title{
O projeto Corrupteca: uma ferramenta analítica para a análise do fenômeno da corrupção
}

\author{
Autor(es): $\quad$ Mesquita, Nuno Coimbra; Moisés, José Álvaro; Eldasi, Giovanni \\ Publicado por: Imprensa da Universidade de Coimbra \\ URL \\ persistente: \\ URI:http://hdl.handle.net/10316.2/36964 \\ DOI: \\ DOI:http://dx.doi.org/10.14195/2183-5462_26_4 \\ Accessed : $\quad$ 26-Apr-2023 12:37:37
}

A navegação consulta e descarregamento dos títulos inseridos nas Bibliotecas Digitais UC Digitalis, UC Pombalina e UC Impactum, pressupõem a aceitação plena e sem reservas dos Termos e Condições de Uso destas Bibliotecas Digitais, disponíveis em https://digitalis.uc.pt/pt-pt/termos.

Conforme exposto nos referidos Termos e Condições de Uso, o descarregamento de títulos de acesso restrito requer uma licença válida de autorização devendo o utilizador aceder ao(s) documento(s) a partir de um endereço de IP da instituição detentora da supramencionada licença.

Ao utilizador é apenas permitido o descarregamento para uso pessoal, pelo que o emprego do(s) título(s) descarregado(s) para outro fim, designadamente comercial, carece de autorização do respetivo autor ou editor da obra.

Na medida em que todas as obras da UC Digitalis se encontram protegidas pelo Código do Direito de Autor e Direitos Conexos e demais legislação aplicável, toda a cópia, parcial ou total, deste documento, nos casos em que é legalmente admitida, deverá conter ou fazer-se acompanhar por este aviso.

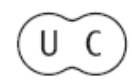




\section{Media Jornalismo}

\section{CORRUPÇÃO POLÍTICA, MEDIA E DEMOCRACIA}




\title{
O PROJETO CORRUPTECA - UMA FERRAMENTA ANALÍTICA \\ PARA A ANÁLISE DO FENÔMENO DA CORRUPÇÃO \\ THE CORRUPTECA PROJECT - AN ANALYTICAL TOOL FOR \\ THE ANALYSIS OF ISSUES RELATED TO CORRUPTION
}

\section{NUNO COIMBRA MESQUITA, JOSÉ ÁLVARO MOISÉS E GIOVANNI ELDASI}

NUPPS@USP.BR

\begin{abstract}
Resumo
A corrupção política é um dos problemas mais severos e complexos enfrentados por novas e velhas democracias. A pesquisa acadêmica já abordou o papel de fatores gerais responsáveis pelo seu enraizamento no sistema político. Entretanto, falta avaliar o quanto ela afeta a qualidade da democracia, além da influência da cultura política na sua ocorrência. A Corrupteca é uma biblioteca digital especializada no tema da corrupção que visa preencher essa lacuna. 0 seu objetivo principal é subsidiar as pesquisas e análises sobre o fenômeno da corrupção no Brasil e no mundo. A ideia é que os interessados possam avaliar, para além de outros objetivos de conhecimento, a influência da corrupção na relação de confiança dos cidadãos com as instituições da democracia.
\end{abstract}

\section{Palavras-chave}

Corrupção Política, Democracia, Instituiçõos Democráticas, Cultura Política.

\section{Abstract}

Political corruption is one of the most severe and complex problems faced by new and old democracies. Academic research has addressed the role of general factors responsible for its roots in the political system. However, the issue of how it affects the quality of democracy - as well as how political culture influences its occurrence - is still to be addressed. Corrupteca is a digital library specialized in the theme of corruption, aiming to fill this gap. Its main objective is to support the research and analysis of the phenomenon of corruption in Brazil and worldwide. The idea is that the public can evaluate - in addition to other educational objectives the influence of corruption in trust between citizens and democratic institutions.

\section{KEYWORDS}

Political Corruption, Democracy, Democratic Institutions, Political Culture. 


\title{
O PROJETO CORRUPTECA - UMA FERRAMENTA ANALÍTICA \\ PARA A ANÁLISE DO FENÔMENO DA CORRUPÇÃO \\ THE CORRUPTECA PROJECT - AN ANALYTICAL TOOL FOR \\ THE ANALYSIS OF ISSUES RELATED TO CORRUPTION
}

\author{
NUNO COIMBRA MESQUITA, JOSÉ ÁLVARO MOISÉS \\ E GIOVANNI ELDASI | UNIVERSIDADE DE SÃO PAULO
}

NUPPS@USP.BR

INTRODUÇÃO

A Corrupteca é uma biblioteca digital especializada no tema da corrupção'. 0 seu objetivo principal é subsidiar as pesquisas e análises sobre o fenômeno da corrupção no Brasil e no mundo. A premissa do projeto é que na atual etapa de conhecimento do tema uma das principais prioridades é oferecer aos interessados - pesquisadores, estudantes, jornalistas e público em geral - uma ferramenta adequada para a observação, análise e compreensão do fenômeno. 0 projeto tem um pressuposto normativo, qual seja, o de que o controle e o combate à corrupção são parte da dimensão republicana da democracia.

A razão disso é que a corrupção política é um dos problemas mais severos e complexos enfrentados por novas e velhas democracias. No fundamental, ela envolve 0 abuso do poder público para qualquer tipo de benefício privado, inclusive, vantagens para os partidos de governo em detrimento da oposição. Ela frauda, portanto, o princípio de igualdade política inerente à democracia, pois os seus protagonistas podem obter ou manter poder e benefícios políticos desproporcionais aos que alcançariam através de modos legítimos e legais de competir politicamente. Ao mesmo tempo, ela distorce a dimensão republicana da política moderna porque faz as políticas públicas resultarem, não do debate e da disputa aberta entre projetos diferentes, mas de acordos de bastidores que favorecem interesses espúrios. Os relatos sobre os casos mais recentes investigados no Brasil, o Mensalão e o caso da Petrobras, demonstram isso fartamente.

0 conhecimento convencional sobre a corrupção mostra que ela envolve 0 abuso do poder público para qualquer tipo de benefício privado, inclusive, vantagens para os partidos que ocupam o governo, em evidente detrimento da oposição. Até recentemente, a pesquisa acadêmica abordou o papel de fatores gerais responsáveis pelo seu enraizamento no sistema político: o desenvolvimento econômico, o desenho institucional, o perfil psicológico dos atores, o desempenho de governos, etc. Não abordou, contudo, o quanto ela afeta a qualidade da democracia, nem a influência

1 A Corrupteca - Biblioteca Internacional da Corrupção (http://corrupteca.nupps.usp.br/) é um projeto do Núcleo de Pesquisa de Políticas Públicas - NUPPs, da Universidade de São Paulo realizado em cooperação acadêmica com a Vérsila Educacional e o Jornal "O Estado de S. Paulo", contando ainda com o apoio da FAPESP - Fundação de Apoio à Pesquisa do Estado de São Paulo e do CNPq - ConseIho Nacional de Desenvolvimento Científico e Tecnológico do Brasil. 
da cultura política na sua ocorrência. Por essa razão, um dos principais objetivos da Corrupteca é precisamente oferecer as condições para que os analistas possam responder algumas dessas perguntas. A ideia é que os interessados possam avaliar, para além de outros objetivos de conhecimento, a influência da corrupção na relação de confiança dos cidadãos com as instituições da democracia, já que o fenômeno de desconfiança política no Brasil e alhures têm demonstrado que afeta a legitimidade do regime democrático e, nessa medida, a sua qualidade.

Em vista disso, são os seguintes os objetivos práticos da Corrupteca:

- Tornar-se uma biblioteca pioneira, de referência internacional, sobre o tema da corrupção, oferecendo suporte informacional e científico a gestores públicos, imprensa, comunidade científica, juristas e o grande público;

- Disponibilizar a memória estruturada e de fácil acesso dos acontecimentos relativos aos casos de corrupção brasileiros para pesquisadores, a imprensa e a sociedade civil;

- Disponibilizar a compilação da produção científica nacional e internacional especializada e documentos jurídicos de domínio público que sejam marcos de casos de corrupção brasileiros, tendo em vista a comunidade acadêmica, juristas e gestores públicos;

- Ser um acervo colaborativo, aberto, gratuito, reproduzível e de texto completo;

0 projeto da Corrupteca se desenvolve no Núcleo de Pesquisa de Políticas Públicas da Universidade de São Paulo como parte de um projeto mais amplo de pesquisa cujo foco é avaliação da democracia brasileira em seus 25 anos de existência.

\section{Acervos e Tecnologia da Corrupteca}

A Corrupteca possui quatro grandes acervos digitais de texto completo e acesso livre, cada qual com cerca de 100 mil volumes digitais, formando um montante total de aproximadamente 400 mil volumes digitais:

1. Acervo Científico: formado por artigos, monografias, ensaios, periódicos, teses e dissertações acadêmicas relativas à corrupção;

2. Acervo Jurídico: formado por inquéritos, julgados, súmulas, doutrina e atos normativos do poder judiciário relativos à corrupção;

3. Acervo Legislativo: formado por constituições, leis, relatórios de comissões, pareceres, notas técnicas, discursos parlamentares e obras raras do poder legislativo relativas à corrupção;

4. Acervo de Notícias: formado por edições de jornais e fascículos de revistas que noticiem e abordem casos de corrupção.

Estes acervos são formados e atualizados continuamente através da participação da Corrupteca no consórcio internacional Open Archives Initiative (OAI) ${ }^{2}$. Tal consórcio integra bibliotecas digitais, repositórios institucionais, acervos, periódicos

2 http://www.openarchives.org/ ( acessado 15/12/2014). 
e bases de dados de cerca de 5.400 instituições de pesquisa, governos, bibliotecas nacionais, jornais e revistas de 65 países.

\section{A Open Archives Initiative}

A OAl surgiu em 2001 como estratégia e tecnologia de interoperabilidade e compartilhamento de informação na internet. Existem duas modalidades de participação na iniciativa ${ }^{3}$ : a primeira como Data Provider, quando a instituição disponibiliza seu acervo digital para que outras coletem suas informações através dos chamados metadados, a segunda modalidade é a Service Provider, quando uma instituição atua como concentradora e curadora dos metadados dos milhares de outros acervos, oferecendo em um único lugar o serviço de busca de toda a informação.

A Corrupteca - Biblioteca Internacional da Corrupção é, portanto, um Service Provider da Open Archives Initiative que possui uma curadoria temática sobre o fenômeno da Corrupção. Ela coleta e concentra os acervos das 5.400 instituições participantes da OAl e realiza a filtragem e seleção de conteúdos específicos sobre corrupção.

\section{A Ontologia da Corrupção}

Para a realização desta seleção é utilizada a tecnologia de Web Semântica ${ }^{4}$ ou Web 3.0, que aborda a internet como uma Web de significados em superação a uma Web apenas de dados. A Web semântica pretende interpretar a informação da internet através da utilização de representações do conhecimento chamadas ontologias computacionais 5 . No caso da Corrupteca, o Núcleo de Pesquisa de Políticas Públicas da USP, em convênio com a Vérsila Educacional, construiu uma Ontologia Computacional da Corrupção, através da contribuição multidisciplinar de cientistas políticos, juristas, historiadores, jornalistas e arquivistas. Através da Ontologia da Corrupção é possível interpretar os metadados da Open Archives Initiative e coletar apenas o que é relativo à corrupção nos campos científico, jurídico, legislativo e jornalístico.

\section{Integração COM o Acervo Vérsila}

A tarefa de coleta de dados de 5.400 instituições de 65 países participantes da OAl pela Corrupteca é realizada pela integração da biblioteca da Corrupção com o Acervo Vérsila ${ }^{6}$, que é considerado o maior acervo de metadados OAl de toda a América Latina. 0 Acervo Vérsila possui servidores de coleta OAl em quatro continentes, nas cidades de São Paulo (Brasil), Cambridge (Costa oeste dos EUA), São Francisco (Costa leste dos EUA), Dublin (Irlanda), Frankfurt (Alemanha), Pequim (China), Tóquio (Japão) e Sydney (Austrália). Cada um destes servidores realiza coletas de dados ao mesmo tempo nos centros de pesquisa geograficamente próximos nos vários continentes.

\footnotetext{
3 http://www.openarchives.org/pmh/ (acessado 15/12/2014).

4 http://www.w3c.br/Padroes/WebSemantica (acessado15/12/2014).

5 http://www.w3.org/standards/semanticweb/ontology (acessado 15/12/2014).

6 http://acervo.versila.com/ (acessado 15/12/2014).
} 
A Corrupteca, por sua vez, utiliza a Ontologia Computacional da Corrupção para filtrar e captar dos dados OAI do Acervo Vérsila todo o conteúdo internacional pertinente ao fenômeno da corrupção.

\section{Acervo Científico}

Deste modo, a Corrupteca, via o Acervo Vérsila, concentra os acervos de instituições de excelência em todo o mundo. No acervo científico, a Corrupteca concentra os acervos de universidades brasileiras como, por exemplo, a Universidade de São Paulo, a Universidade de Brasília, a Universidade Federal do Rio Grande do Sul e a Fundação Getúlio Vargas. Em Portugal, estão integrados, por exemplo, os acervos da Universidade de Lisboa, Universidade de Coimbra, Universidade do Porto e Universidade do Minho. De outros países, merecem destaque os acervos integrados da Universidade de Harvard, Massachusetts Institute of Technology, Yale University, Standford University, Oxford University, Cambridge University, Université de Paris, Berlin University, Hamburg University, Universidad Complutense de Madrid, Università di Bologna, Univesità di Roma "La Sapienza".

Em termos de redes de publicações científicas, estão integradas na Corrupteca a Redalyc: La Red de Revistas Científicas de América Latina y el Caribe e o SciELO: The Scientific Electronic Library Online. No campo das Bibliotecas Nacionais, estão integradas a Biblioteca Nacional da Espanha, a Biblioteca Nacional da França e a Biblioteca do Congresso dos Estados Unidos da América.

A ideia é que esse acervo estimule o desenvolvimento de pesquisas comparativas envolvendo o Brasil e outros países;

\section{AcERVo JuRídico}

0 acervo jurídico da Corrupteca concentra todo o Consórcio BDJur ${ }^{7}$ - Biblioteca Digital Jurídica, uma rede de acervos jurídicos mantida pelo STJ - Superior Tribunal de Justiça do Brasil, e reúne inquéritos, jurisprudência, julgados, súmulas, doutrina e atos normativos do tribunal superior e de diversos tribunais regionais do Brasil.

\section{O Acervo Legislativo}

0 acervo legislativo da Corrupteca concentra a Biblioteca Digital do Senado Federal Brasileiro ${ }^{8}$ e disponibiliza constituições, leis, relatórios de comissões, pareceres, notas técnicas, discursos parlamentares e obras raras da Câmara de Deputados e do Senado do Brasil.

\section{Acervo de Notícias - Integração com o Acervo "O Estado de S. Paulo"}

0 acervo de notícias da Corrupteca é formado destacadamente pelo Acervo Digital do jornal "0 Estado de S. Paulo"9 ou "Estadão", um dos principais e mais antigos jornais impressos do Brasil, que em parceria exclusiva com a Corrupteca

7 http://www.consorciobdjur.gov.br/ (acessado 15/12/2014).

8 http://www2.senado.leg.br/bdsf/ (acessado 15/12/2014).

9 http://acervo.estadao.com.br/ (acessado 15/12/2014). 
disponibiliza a totalidade de seu acervo de notícias desde 0 ano de sua fundação em 1875, também via a metodologia OAl. Além do acervo "Estadão", a Corrupteca integra a "Prensa Histórica"10, uma hemeroteca iniciativa do Ministério da Cultura da Espanha que digitalizou jornais e revistas de 2.446 editores daquele país, compreendendo edições e fascículos desde 0 ano 1797 até os dias atuais.

\section{As Coleções da Corrupteca}

De acordo com boas práticas internacionais de arquivística digital, a Corrupteca disponibiliza ao público três coleções especiais:

1. Coleção Casos: que de maneira sistemática compila notícias, peças judiciais, relatórios, vídeos e reportagens dos principais Casos de Corrupção no Brasil. A informação é disposta em infográficos no formato de Linhas do Tempo, e os casos recebem os apelidos dados pela imprensa brasileira, tais como "Anões do Orçamento", "Jorgina de Freitas", "Nicolau dos Santos Neto", "Collor/PC Farias", "Mensalão", "Trensalão" e "Petrolão".

2. Coleção Didática: que destaca pequenos artigos didáticos que explicam ao grande público conceitos de corrupção tais como "Lavagem de Dinheiro", "CPI", "Apropriação indébita", "Peculato", etc.

3. Coleção Nacional: que destaca produções científicas ou editoriais que tratem da temática da Corrupção no Brasil.

\section{Plano Institucional}

A Corrupteca, de entre os seus objetivos, realizou um plano institucional para os próximos anos, de modo a ampliar ainda mais o seu acervo, qualificar a sua tecnologia e o acesso de seu público-alvo.

Em sua infraestrutura, a Corrupteca está desenvolvendo um aplicativo para tablets que permitirá o acesso completo a seus recursos por meio destes dispositivos móveis, contando ainda com a funcionalidade do cadastro e identificação dos usuários de modo a formar cada um portfólio que registre de maneira pessoal os resultados escolhidos das pesquisas no acervo para posterior consulta.

Em seu acervo, na Coleção Casos pretende-se a inserção de novos casos de corrupção brasileiros; a Coleção Didática será cada vez mais ampliada através da colaboração de pesquisadores e especialistas que traduzam o tema da corrupção à população; a Coleção Nacional será ampliada de acordo com novos destaques de trabalhos e publicações nacionais que tratem da temática da Corrupção. Em seu Acervo de Notícias, pretende-se o estabelecimento de novos acordos de cooperação com acervos de imprensa, especialmente do Brasil e de Portugal, de maneira semelhante ao operado com o jornal "O Estado de S. Paulo".

\section{ESCÂNDALOS DE CORRuPÇÃo}

A corrupção política frauda a igualdade de condições necessária para a competição política em regimes democráticos, desequilibrando o processo de tomada de

10 http://prensahistorica.mcu.es/ (acessado 15/12/2014). 
decisões mediante a apropriação privada de fundos públicos. Além de a corrupção política comprometer processos democráticos, ela também afeta a legitimidade do regime, induzindo os cidadãos a desacreditarem no princípio do primado da lei, em especial quando aqueles envolvidos em malfeitos não são punidos pelas instâncias judiciárias.

Dessa forma, esse comprometimento da legitimidade é especialmente afetado no caso de grandes escândalos de proporção nacional. Há indícios de que esses escândalos podem fomentar a maior percepção da corrupção como um problema por parte dos cidadãos. Por outro lado, o enfoque em determinados casos por parte da mídia também pode estimular os próprios órgãos de integridade do Estado a funcionarem (Mesquita, Moisés e Rico, 2014). No recente período democrático brasileiro, o país se viu defrontado com vários desses escândalos. A "coleção casos" da Corrupteca apresenta os principais episódios, com uma linha do tempo dos acontecimentos relacionados ao caso e como ele se encontra atualmente, do ponto de vista judicial. Todos receberam grande atenção da mídia.

Jorgina de Freitas (1991): Um dos primeiros escândalos de grande proporção do período democrático brasileiro ficou conhecido como a "Máfia da Previdência", ou caso "Jorgina de Freitas", uma de seus principais personagens, que foi identificada como a líder do grupo que fraudou o Instituto Nacional de Seguro Social (INSS). A fraude consistia em forjar indenizações milionárias - como ações indenizatórias em nome de pessoas pobres (e até falecidas), que não recebiam o dinheiro uma vez concedida a indenização - nas varas de acidente de trabalho no estado do Rio de Janeiro. 0 golpe contava com a participação de advogados, contadores e procuradores do INSS. 0 esquema foi exposto em 1991. Após a descoberta de aposentadorias milionárias em um dos municípios do Rio de Janeiro, uma investigação foi aberta pela justiça estadual, quando foram desvendados outros casos da fraude.

Ainda em 1991 foi aberta uma Comissão Parlamentar Mista de Inquérito (CPMI) para investigar o caso, e em abril do mesmo ano a Procuradoria de Justiça do Rio de Janeiro apresentou a denúncia do caso. 0 processo durou um ano, quando todos os 18 réus foram condenados pelos crimes de peculato e apropriação indevida, além de terem seus bens indisponibilizados pela justiça. A principal personagem do caso, Jorgina de Freitas, ficou foragida da justiça por cinco anos, mas foi finalmente presa, cumprindo pena em regime fechado entre 1998 e 2007, e em regime semi-aberto até 2010. A Justiça de Miami, nos EUA, também condenou Jorgina a devolver aos cofres públicos brasileiros US\$123 milhões desviados da Previdência do Brasil.

Collor (PC Farias) (1992): Em 1989 o Brasil elegeu seu primeiro presidente da República de forma direta após 25 anos de regime autoritário. Fernando Collor de Mello foi eleito por um partido inexpressivo, o PRN, e com um forte discurso anti-corrupção. Seu governo, entretanto, foi ele próprio alvo de diversas denúncias de malfeitos, desde o início de sua gestão. Foi em 1992 que vieram à luz, através de uma reportagem da Revista Veja, denúncias de atividades ilícitas suas com seu ex-tesoureiro de campanha, Paulo César Farias. A denúncia foi feita pelo irmão do então presidente, Pedro Collor.

As dinâmicas de grandes escândalos de corrupção, em geral, se desenvolvem com o desdobramento de um número grande de fatos e denúncias, que começam a vir à tona ao longo do tempo, sendo noticiados pelos meios de comunicação. Com 
esse caso não foi diferente. Após a primeira denúncia de que PC Farias era um "testa-de-ferro" do Presidente, várias outras reportagens se seguiram. Autoridades afirmaram terem sido pressionadas pelo ex-tesoureiro do Presidente a fazerem negócios fora da margem da lei, indicando que o personagem fortemente ligado a Collor exercia tráfico de influência no governo.

Mediante uma Comissão Parlamentar Mista de inquérito (CPMI), o Congresso brasileiro abriu um processo investigativo. Para comprovar que PC Farias não pagava as contas do Presidente, criou-se uma versão de que recursos de um empréstimo no Uruguai para a campanha eleitoral eram os responsáveis pelo custeio do Presidente. Quando se verificou que os documentos para a comprovação do empréstimo foram forjados, complicou-se ainda mais a situação de Collor. A CPMI, entre outros ilícitos, comprovou o desvio de US\$6,5 milhões para o pagamento de gastos pessoais do Presidente e para favorecer aliados políticos.

A Câmara dos Deputados aprovou a abertura do processo de impeachment de Collor, que acabou afastando-o da política por oito anos. Apesar disso, foi absolvido em 1994 pelo Supremo Tribunal Federal por falta de provas. Já seu ex-tesoureiro, PC Farias, foi condenado por falsidade ideológica a sete anos de prisão, mais multa. Depois de cumprir os oito anos de suspensão de seus direitos políticos, Fernando Collor voltou à política e se elegeu senador da República por Alagoas em 2006.

Anões do Orçamento (1993): Apenas após um ano do impeachment de Collor, surgiu um outro grande escândalo de corrupção, desta vez na Comissão Mista de Orçamento no Congresso. 0 caso ficou conhecido como "escândalo dos anões" devido à baixa estatura dos congressistas envolvidos. Mais uma vez a imprensa desencadeou o escândalo. Em entrevista à Revista Veja, um ex-assessor da Comissão de Orçamento denunciou o esquema.

No sistema político brasileiro, existe a previsão de emendas feitas ao Orçamento Geral da União. Esta é de responsabilidade do executivo, que a submete ao Congresso. As emendas permitem que parlamentares possam influir na alocação de recursos públicos para seus municípios ou estados de origem. 0 esquema de corrupção descoberto consistia em fraudar esse mecanismos. Os deputados da Comissão recebiam suborno de prefeitos para liberar obras para as suas cidades e de empreiteiras para o seu favorecimento em obras públicas. Outra fraude ocorria quando se aprovava subvenções dos ministérios para entidades assistencialistas fictícias, controlados pelos próprios parlamentares.

Como usual quando há denúncias de grandes escândalos de corrupção no Brasil, também se abriu uma comissão investigativa no Congresso. 0 processo resultou na cassação de seis parlamentares e a renúncia de mais quatro.

Nicolau dos Santos Neto (2000): É certo que o jornalismo investigativo tem papel importante ao trazer a luz denúncias de corrupção que podem acionar os mecanismos de controle do estado. Mas também está claro que por vezes a atenção que a mídia dá a determinados casos acontece após o sistema de integridade começar a funcionar. Um desses casos foi o superfaturamento da obra de um prédio do Tribunal Regional do Trabalho de São Paulo (TRT-SP). A concorrência para as obras ocorreu em 1992. Ainda no mesmo ano, uma comissão do Tribunal de Contas da União apontou várias irregularidades no processo licitatório, tendo, em 
1996, detectado superfaturamento de grande parte dos recursos pagos pelo tesouro. Em 1998 o Ministério Público Federal ajuizou uma Ação Civil Pública contra 0 Juiz Nicolau do Santos Neto, presidente do TRT, e os empresários das respectivas empresas envolvidas na construção do prédio.

Uma Comissão Parlamentar de Inquérito no Senado foi aberta em 1999 para apurar denúncias relacionadas à atuação do poder judiciário. É só então que a mídia passa a noticiar o caso, após sete anos de iniciado o processo pelos mecanismos de controle do Estado. A partir daí, os meios de comunicação dão grande cobertura ao caso, em especial no ano de 2000. Mesmo não tendo sido responsável pelo desencadeamento das investigações pelo poder público, a mídia ajudou a pressionar o sistema por respostas políticas. Ainda em 2000, o empresário Luiz Estevão, proprietário de uma das empresas envolvidas e também senador da República, teve seu mandato cassado, o primeiro senador a ser cassado no período democrático brasileiro. 0 Juiz Nicolau teve várias condenações e chegou a cumprir prisão temporária, mas só teve a primeira condenação definitiva em 2013. No mesmo ano a União conseguiu recuperar parte do dinheiro desviada pelo juiz na década de 90.

SUDAM (2001): A Superintendência do Desenvolvimento da Amazônia (Sudam) é uma autarquia do governo federal do Brasil. Ela é responsável por promover o desenvolvimento da região amazônica mediante incentivos fiscais e financeiros especiais. Ainda em 1997, o Ministério Público Federal no Estado do Mato Grosso havia identificado irregularidades em contratos realizados entre a Sudam e uma empresa têxtil. Apesar da investigação à época, o caso ainda não havia sido explorado nos meios de comunicação.

Além do jornalismo investigativo, são os adversários políticos outro grande desencadeador de denúncias de corrupção que atingem proporções nacionais. Em 2001, Jader Barbalho (PMDB-PA) é eleito presidente do Senado, substituindo seu desafeto Político, Antônio Carlos Magalhães (PFL-BA). ACM, como era conhecido, apresenta um relatório obtido do Banco Central contra Jader, acusando-o de fraude contábil. A acusação inicial era de desvio de recursos do Banco do Estado do Pará (Banpará), durante o período em que Jader foi governador (1983-1987). Com o senador paraense sob alvo de investigação, surgem provas de que ele estaria ligado também às fraudes da Sudam. Com um desgaste de meses pelas acusações de sua atuação no caso Banpará e Sudam, Jader Barbalho renuncia ao cargo de Senador para escapar de um processo de cassação. Apesar de Procuradores da República e Polícia Federal terem concluído que houve um desvio de $\mathrm{R}$ \$ 1,3 Bilhão na Sudam, com pelo menos $R \$ 700$ milhões enviados a paraísos fiscais, até 2014 Jader BarbaIho não havia sido condenado judicialmente. Se elegeu deputado em 2002 e 2006 e senador em 2010.

Mensalão (2005): Em 2005 veio à luz um dos maiores escândalos de corrupção do Brasil. Apesar de a acusação principal ser a distribuição de dinheiro do executivo a parlamentares da base governamental em troca de apoio político, 0 período foi caracterizado por um número grande de outras denúncias e investigações de irregularidades. 0 início da crise se deu com a divulgação de uma fita de vídeo em que um o ex-diretor da Companhia de Correios foi flagrado relatando um esquema de suborno que teria a participação do presidente do Partido Trabalhista Brasileiro (PTB), Roberto Jefferson. De acordo com as denúncias, 0 
dinheiro arrecadado iria para o partido de Jefferson. Na gravação, Marinho afirmou também que outras estatais federais possuiriam esquemas semelhantes. Diante dessas informações, as lideranças do Partido da Frente Liberal (PFL) e do Partido da Social Democracia Brasileira (PSDB) propuseram a criação de uma Comissão Parlamentar Mista de Inquérito (CPMI) para investigar as denúncias de corrupção, tendo como foco os Correios e outras estatais.

Em geral, o desencadeamento de um escândalo de corrupção se dá com o jornalismo investigativo ou com a denúncia de algum desafeto político. No caso do Mensalão, o pivô da crise que se seguiu foi o deputado e presidente do PTB, que após as denúncias em relação ao seu próprio partido, resolveu acusar um outro esquema de corrupção dentro da própria coalizão da qual fazia parte. Em entrevista ao jornal Folha de S.Paulo no início de junho de 2005, o deputado federal Roberto Jefferson afirmou que deputados do Partido Progressista (PP) e do Partido Liberal (PL) recebiam do tesoureiro do Partido dos Trabalhadores (PT), Delúbio Soares, R\$ 30 mil mensais em troca de votos a favor de projetos de interesse do Executivo. Jefferson cunhou o neologismo Mensalão, que ficou conhecido e utilizado sempre pelos meios de comunicação para se referir a esse episódio.

A comissão parlamentar de inquérito que havia sido aberta para apurar as denúncias de irregularidades nos correios, passa, então, a investigar também esse esquema de compra de votos no congresso. Também foi criada a CPMI da compra de votos, com o objetivo específico de averiguar essa denúncia. Outras revelações novas, seguidas de investigações, acabaram expondo irregularidades também no financiamento de campanhas políticas. A partir de então, o jornalismo investigativo, juntamente com o trabalho das comissões de inquérito, passaram a desvendar uma série de irregularidades que vieram a público. Além da compra de votos, foram denunciados esquemas de empréstimos fraudulentos junto a bancos para a arrecadação do dinheiro utilizado no esquema.

Na época do escândalo, surgiram informações sobre a participação de empresas portuguesas. 0 Banco Espírito Santo afirmou que um dos principais personagens acusados de liderar o núcleo operacional do esquema do Mensalão - o publicitário Marcos Valério de Souza - conseguiu agendar um encontro entre o então Ministro da Casa Civil, José Dirceu, e o presidente da Instituição, Ricardo Espírito Santo. A Portugal Telecom é uma das maiores credoras das empresas da área não financeira do Grupo Espírito Santo, no Brasil. As agências de Publicidade de Marcos Valério prestavam serviços a empresas telefônicas controladas pelo grupo Opportunity e que eram de interesse da Portugal Telecom.

Um episódio que envolvia o Grupo Espírito Santo foi utilizado por diversas vezes durante 0 Julgamento do processo pelo Supremo Tribunal Federal (STF) para condenar políticos. Roberto Jefferson afirmou em depoimento que José Dirceu o havia incumbido, juntamente com o então tesoureiro do PTB, Emerson Palmieri, a se reunir com o presidente da Portugal Telecom, Miguel Horta e Costa, e obter recursos ilegais da empresa portuguesa para os dois Partidos (PT e PTB).

Já depois do início do julgamento do caso pelo Supremo Tribunal Federal, Marcos Valério também acusou o ex-presidente Lula de ter negociado com Miguel Horta e Costa, o repasse de R\$ 7 milhões para o PT. Além de Miguel Horta e Costa, 0 publicitário afirmou ter-se reunido com o ministro das Obras Públicas de Portugal 
António Mexia. Miguel Horta e Costa e António Mexia chegaram a ser arrolados como testemunhas no processo e chegaram a testemunhar em Lisboa. Entretanto, Marcos Valério recusou a oferta de delação premiada e, por falta de provas, nenhum português foi indiciado.

0 escândalo do Mensalão produziu resultados políticos logo no início das denúncias. José Dirceu, Roberto Jefferson e Pedro Corrêa (presidente do PP) foram cassados pelo Congresso. Mais quatro parlamentares envolvidos renunciaram para não correr o risco de terem seus direitos políticos suspensos. Além disso, houve uma crise interna no partido dos trabalhadores. Alguns quadros foram expulsos, enquanto outros acabaram deixando o partido. Em 2006 o Procurador-Geral da República apresentou a denúncia ao STF. Em 2007 a suprema corte brasileira aceita a denúncia contra os 40 acusados, que acaba sendo convertida na ação penal 470. 0 julgamento só iniciou em 2012. Após mais de quatro meses, o mais longo julgamento da história do STF, foram condenados vinte e cinco dos acusados.

Mensalão mineiro (2005): Uma das características de grandes escândalos de corrupção é a denúncia inicial feita ou por veículos do jornalismo investigativo, por rivais políticos de envolvidos em malfeitos ou até por ex-aliados, que conhecem 0 esquema por dentro e, por alguma mudança de circunstância, passam a denunciar o próprio esquema de que foram partícipes. Outra característica igualmente notável é que, em geral, após uma denúncia inicial, não é possível prever onde o desenrolar das investigações original vai resultar. Tanto o próprio jornalismo investigativo, quanto o sistema de integridade que passa a ser acionado, podem trazer a luz novas informações, denúncias e personagens envolvidos.

Foi o que aconteceu em 2005, quando a partir de uma denúncia de corrupção nos correios, uma série de investigações e novos desdobramentos acabou na denúncia e condenação de vinte e cinco pessoas por uma série de crimes, não correlatos a denúncia original. Além do próprio crime de compra de votos desvendado, foi descoberto também um esquema semelhante durante a instauração da CPMI dos correios, ainda no ano de 2005. 0 caso ficou conhecido como Mensalão "mineiro" ou "tucano", em referência tanto a sua origem ser no estado de Minas Gerais, quanto atingir o partido da oposição, o PSDB (o pássaro tucano é o símbolo do partido).

A acusação do Ministério Público é que houve um financiamento irregular da campanha para reeleição do governador de Minas Gerais, Eduardo Azeredo (PSDB) em 1998. 0 caso veio à tona nas investigações da CPMI, pois o principal operador do Mensalão do governo federal, Marcos Valério, foi o mesmo que apareceu como tendo participado do desvio de recursos públicos de estatais mineiras para 0 uso no "caixa 2" de campanha. Empresas estatais teriam repassado verbas para as agências de publicidade de Valério, que não prestaram os serviços contratados, tendo repassado o dinheiro para gastos de campanha, além de para seu próprio benefício.

0 Ministério Público entregou a acusação em 2007. 0 processo contra vários dos envolvidos chegou a tramitar no Supremo Tribunal Federal. Porém, com a renúncia dos parlamentares envolvidos, que deixaram de ter foro privilegiado, o processo foi remetido para a justiça de primeira instância em 2014. 
Caso Petrobrás (2014): As primeiras denúncias de corrupção em uma das principais empresas estatais brasileiras (de economia mista), a Petrobrás, foram denunciadas no jornal 0 Estado de São Paulo em março de 2014. Essas denúncias iniciais davam conta da compra da refinaria Pasadena, nos EUA, por parte da empresa brasileira. A compra foi denunciada como tendo indícios de irregularidades, já que a Petrobrás pagou em 2006 US\$ 1,18 Bilhões, sendo que no ano anterior a empresa belga Alton havia pago pela mesma refinaria apenas US\$ 42,5 milhões.

Mais denúncias na imprensa a respeito de irregularidades em licitações da estatal se seguiram. Uma delas diz respeito a uma refinaria no Estado de Pernambuco, a Abreu e Lima. Inicialmente a obra deveria ser feita em pareceria com a PDVSA (empresa estatal de petróleo da Venezuela). A situação jurídica, entretanto, nunca chegou a ser formalizada e o governo venezuelano não chegou a investir nenhuma quantia na obra, tendo a Petrobrás arcado com seu custo total. 0 Tribunal de Contas da União (TCU), após auditorias, concluiu que houve superfaturamento em alguns contratos. De um custo inicial previsto de US\$ 2 Bilhões, o gasto efetivo da obra chegou a US\$ 18 Bilhões.

O TCU encontrou irregularidades em outras obras da Petrobrás, onde se observou superfaturamento de alguns contratos, além de contratações por parte da Estatal de maneira simplificada, fora do que é determinado pela Lei de Licitações. Nesta situação, se enquadram a construção do gasoduto Urucu-Manaus e o contrato da manutenção e recuperação do sistema de óleo e gás da região sudeste.

Essas e outras irregularidades na Petrobrás começaram a ser investigadas por uma operação da Polícia Federal brasileira, conhecida por Operação Lava Jato. Ela foi deflagrada em março de 2014. 0 doleiro Alberto Youssef, apontado como um dos operadores do esquema de corrupção, além do ex-diretor de abastecimento da Petrobrás, Paulo Roberto Costa, foram presos e, posteriormente assinaram acordos de delação premiada com o Ministério Público em troca de terem suas penas aliviadas. Costa afirmou que havia um esquema de suborno em obras da estatal, sendo que o dinheiro seria desviado para o caixa dos partidos como o PT o PP e o PMDB. Em dezembro de 2014, a Procuradoria da República ofereceu denúncia e a Justiça Federal do Estado do Paraná aceitou. No início de 2015 eram 39 os réus indiciados.

Breves Considerações finais: A contribuição da Corrupteca para 0 estudo da corrupção

A corrupção política é um dos maiores problemas enfrentados pelas democracias. 0 abuso do poder público frauda o princípio de igualdade política inerente à democracia, além de distorcer a dimensão republicana da política. A pesquisa acadêmica já abordou o papel de fatores gerais responsáveis pelo enraizamento da corrupção no sistema político. Entretanto, há uma lacuna no estudo da corrupção como fator que afeta a qualidade da democracia, além da cultura política. Assim, a Corrupteca é um instrumento que objetiva oferecer as condições para o estudo da corrupção neste contexto, fomentando a pesquisa, ampliando a transparência e difundindo informações sobre o fenômeno da corrupção, pretende fornecer subsídios para a formulação de políticas para seu combate por parte de pesquisadores e gestores públicos, para o aumento da qualidade da informação vinculada pela imprensa e para a ação cidadã da população em geral. 
BibliogRAfia

Arnold, A.-K. \& Lal, S. (2012). Using Media to Fight Corruption, Partnership for Transparency Fund. Working Paper Series 1.

Brunetti, A. \& Weder, B. (2003). A free press is bad news for corruption. Journal of Public Economics 87: 1801-1824.

Chang, E. C. C., Golden, M. A. \& Hill, S. J. (2010). Legislative Malfeasance and Political Accountability. Cambridge. World Politics 62 (2): 177-220.

Corrupteca - Biblioteca Internacional da Corrupção (http://corrupteca.nupps.usp.br/)

Dahlstrom, T. (2008). The Role of Media in Combating Corruption. Atenas. Paper apresentado no Patterns of Corruption in the 21st Century. 6 e 7 de setembro de 2008.

Ferraz, C. \& Finan, F. (2008). Exposing Corrupt Politicians: The Effects of Brazil's Publicly Released Audits on Electoral Outcomes. The Quarterly Journal of Economics 123 (2):703-745.

Machado, M. (2011). Combate à corrupção no Brasil e Argentina, caso TRT. Paper apresentado no I Encontro de Pesquisa Empírica em Direito, Faculdade de Direito de Ribeirão Preto da Universidade de São Paulo (FDRP/USP). 29 e 30 de setembro de 2011.

Mesquita, N. C., Moisés, J.A. \& Rico, B. (2014). Diferentes Dinâmicas da Corrupção: Mídia, Percepção e Instituições no Contexto Brasileiro. In: Cunha, I. F. \& Serrano, E. (coords.). Cobertura Jornalística da Corrupção Política (pp. 283-316). Lisboa: Alêtheia.

Odugbemi, S. \& Norris, P. (2009). Do the news media act as watchdogs, agenda setters and gate keepers? In: Norris, P. (ed.). Public sentinel: news media \& governance reform. Washington D.C.: World Bank.

Smulovitz, C. \& Peruzzotti, E. (2000). Societal Accountability in Latin America, Journal of Democracy 11 (4): 147-158. Project MUSE. Web. 19 Dec. 2012. (http://muse.jhu.edu/).

Stapenhurst, R. (2000). The Media's Role in Curbing Corruption. WBI working papers. World Bank Institute 